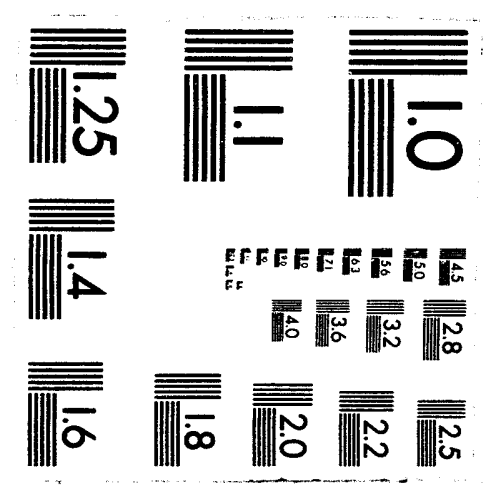



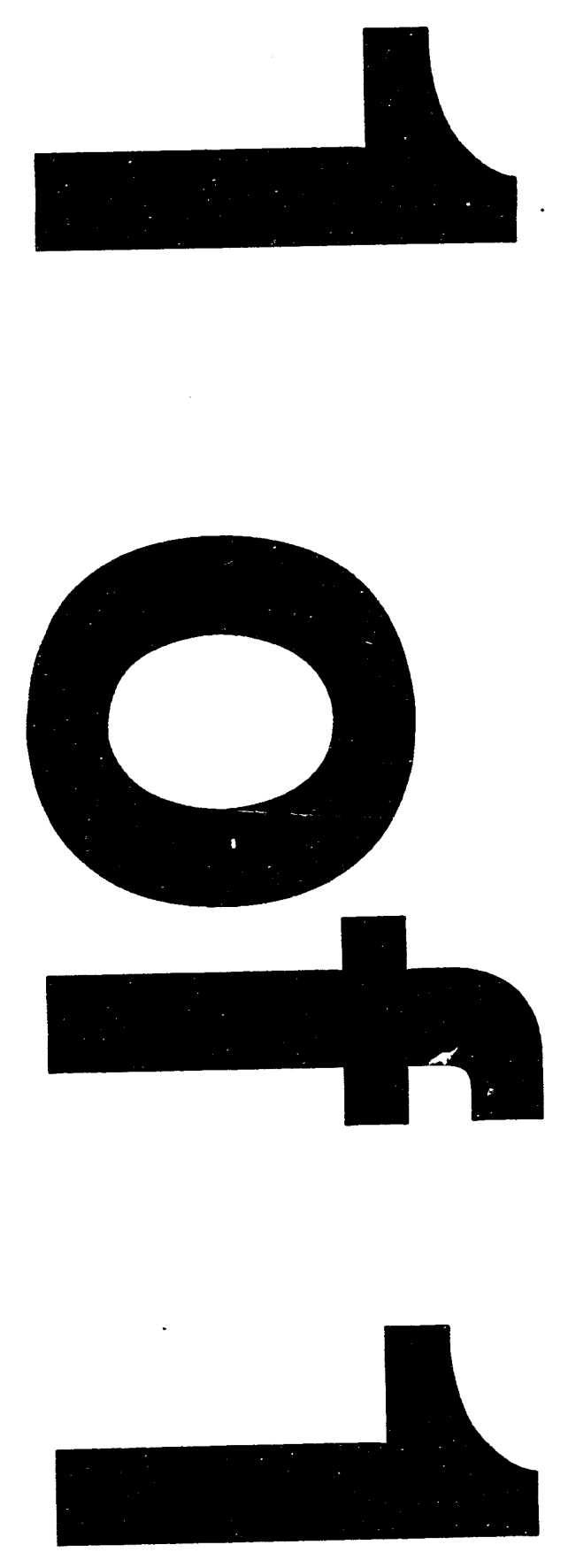


\title{
CROSS-CONDENSATION REACTIONS IN AN ORGANICALLY MODIFIED SILICA SOL-GEL
}

\author{
S. PRABAKAR* , R. A. ASSINK ${ }^{* *}$, N. K. RAMAN* and C. J. BRINKER*, ** \\ ${ }^{*}$ UNM/NSF Center for Micro-Engineered Ceramics, University of New Mexico, \\ Albuquerque, NM 87106 \\ ** Sandia National Laboratories, Albuquerque, NM 97185.
}

\begin{abstract}
High resolution ${ }^{29} \mathrm{Si}$ NMR has been used to study the extent of cross condensation taking place in a hybrid organic/inorganic sol-gel system. Tetraethoxysilane (TEOS) and methyltriethoxysilane (MTEOS) sol-gels were chosen for this purpose. The sols were prepared by acid catalyzed hydrolysis of TEOS and MTEOS with a $\mathrm{H}_{2} \mathrm{O} / \mathrm{Si}$ ratio of 0.3. ${ }^{29} \mathrm{Si}$ NMR shows signals due to both self-condensation and cross-condensation between TEOS and MTEOS. Resonance assignments were made by comparing the positions and intensities of peaks in the spectra of single and multicomponent systems. It was found that, within experimental error, the self- and cross-condensation rates are equal and that extensive molecular level mixing takes place during the early stages of the reaction.
\end{abstract}

\section{INTRODUCTION}

The chemical synthesis of glasses and ceramics provides a convenient method for producing high purity, homogenous materials [1,2]. A general strategy for the design of improved materials has been the synthesis of multicomponent systems. These efforts may take the form of organic/organic copolymers, organic/inorganic hybrids and multicomponent inorganic materials. The effectiveness of the strategy often depends on the degree of mixing of the components. Mixing can be achieved on an intimate level when covalent bonds are formed between components. While a variety of techniques have been employed to study the chemical structure of silica sol-gels [1-3], corresponding studies of hybrid organic /inorganic silica solgels are scarce [4] .

When TEOS is reacted with MTEOS, three kinds of condensed species are possible, two due to self-condensation ( (i) and (ii)) and one due to cross-condensation (iii):

$$
\begin{array}{llll}
\mathrm{T}+\mathrm{T} & -->> & \mathrm{TT} & \text { (i) } \\
\mathrm{Q}+\mathrm{Q} & -->> & \mathrm{QQ} & \text { (ii) } \\
\mathrm{T}+\mathrm{Q} & --> & \mathrm{TQ} & \text { (iii) }
\end{array}
$$

where $\mathrm{T}$ represents the silicon in MTEOS and Q represents the silicon in TEOS. Fyfe et al. [4] studied an amorphous solid material prepared in this manner by ${ }^{29} \mathrm{Si} \mathrm{CP} / \mathrm{MAS}$ NMR. Since the resonances of the solid material were broad, it was difficult to distinguish between species due to self- and cross-condensation. A two-dimensional ${ }^{1} \mathrm{H} /{ }^{29} \mathrm{Si}$ NMR experiment, however, was able to detect the presence of cross-condensed species. In this study we investigate a hybrid sol-gel during the early stages of the reaction using liquid state high resolution ${ }^{29} \mathrm{Si}$ NMR. Because of the increased resolution, we are able to directly observe resonances attributable to species formed by cross-condensation reactions.

This work was supported by the U.S. Department of Energy under Contract DE-AC0494AL8500.

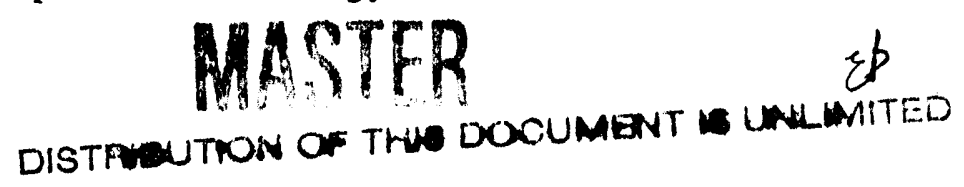




\section{EXPERIMENTAL}

Sols in the system $x$ MTEOS : $(100-x)$ TEOS (where $x=0,50,100$, all in mole percent) were prepared by the acid catalyzed hydrolysis of the respective alkoxides in ethanol with an $\mathrm{H}_{2} \mathrm{O} / \mathrm{Si}$ ratio $(\mathrm{R})$ of 0.3 . Chromium acetylacetonate $(\mathrm{CrAcAc}), 5 \mathrm{mM}$, was added to reduce the ${ }^{29} \mathrm{Si}$ spin lattice relaxation time. Previous studies have detected no effect of the $\mathrm{CrAcAc}$ relaxation agent on the reaction rate or the product distribution of sol-gels [3] ${ }^{29} \mathrm{Si}$ NMR spectra were taken immediately after the samples were mixed and were recorded as a function of time.

The ${ }^{29} \mathrm{Si}$ solution spectra were acquired at $39.6 \mathrm{MHz}$ (magnetic field 4.7T) on a Chemagnetics console interfaced to a General Electric 1280 data station and a pulse programmer. All the spectra were accumulated at room temperature using a $10 \mathrm{~mm}$ probe. Typical spectra were obtained using 256 scans with a pulse delay time of $15 \mathrm{~s}$. A $0.1 \mathrm{~Hz}$ line broadening was employed before Fourier transformation. The line widths of the accumulated spectra were typically $0.3 \mathrm{~Hz}$.

\section{RESULTS AND DISCUSSION}

The full scale spectra of pure MTEOS, pure TEOS and the 50 MTEOS: 50 TEOS hybrid are shown in Fig 1. The spectrum of the MTEOS sol-gel, accumulated during the 5 to $65 \mathrm{~min}$ interval immediately following mixing, is shown in Fig 1(a). It exhibits signals characteristic of $\mathrm{T}^{0}, \mathrm{~T}^{1}$ and $\mathrm{T}^{2}$ where the superscript, $\mathrm{n}=0-3$, refers to the number of bridging oxygens. Fig 1 (b) is the spectrum of hydrolyzed TEOS accumulated during the 5 to $65 \mathrm{~min}$ interval immediately following mixing. The spectrum exhibits resonances due to $\mathrm{Q}^{0}, \mathrm{Q}^{1}$ and $\mathrm{Q}^{2}$ where the superscript, $n=0-4$, again refers to the number of briding oxygens and the subscript, $m$, is the number of hydroxyl groups [5, 6]. The $\mathrm{m}$ is omitted for species which are unhydrolyzed. The ${ }^{29} \mathrm{Si}$ NMR of the MTEOS/TEOS mixture shows resonances in both the $\mathrm{Q}$ and $\mathrm{T}$ regions.

Analysis of the full spectra of the pure MTEOS and pure TEOS reveals several interesting features. MTEOS reacts rapidly and reaches equilibrium within 65 mins as subsequent spectra were essentially identical to the first spectrum. Compared to MTEOS, TEOS reacts slowly and additional products are formed even after $4 \mathrm{~h}$. Thus, the self-condensation of MTEOS is much faster than the self-codensation of TEOS under identical reaction conditions.

In these experiments, the $T$ and $Q$ monomers in the hybrid sol will compete for the limited amount of water availabe for hydrolysis. The relative rate of hydrolysis of $T$ species to $Q$ species is thus reflected by an appropriate sum of the concentrations of their respective hydrolyzed and condensed species in the spectrum of the hybridized. For example, $\mathrm{Q}^{0}{ }_{1}$ and $\mathrm{T}^{1}$ silicons have undergone 1 hydrolysis reaction each while a $\mathrm{T}^{2}$ silicon has undergone 2 hydrolysis reactions. This calculation assumes that the rate of alcohol producing condensation is much less than the rate of water producing condensation [7]. The relative rate of hydrolysis of $T$ to $Q$ species was calculated to be 2.4 for this acid catalyzed system. Since the water content is quite low, the rate corresponds primarily to the first hydrolysis of each monomeric species.

The primary positions of the $\mathrm{T}$ and $\mathrm{Q}$ silicons, as shown in Fig 1, are determined by the nearest functional groups. For example, all of the resonances near -51.0 and $-88.8 \mathrm{ppm}$ correspond to $\mathrm{T}^{1}$ and $\mathrm{Q}^{1}$ silicons, respectively. If we expand these regions, as shown in Fig 2(a) and (b), we find that each resonance is actually composed of several components which corrrespond to the various functionalities of the adjacent silicon. The assignments were made by recognizing that the intensity of symmetric species such as $T^{1} T^{1}$ and $Q^{1} Q^{1}$ are independent of the intensity of any other resonance in the spectrum, while the intensity of the resonance assigned to the $T^{1} T^{2}$ species always tracked the intensity of a resonance in the $T^{2}$ region. The assignments of these species are listed in Table1. The spectra in Figs 2(a) and (b) correspond to species 

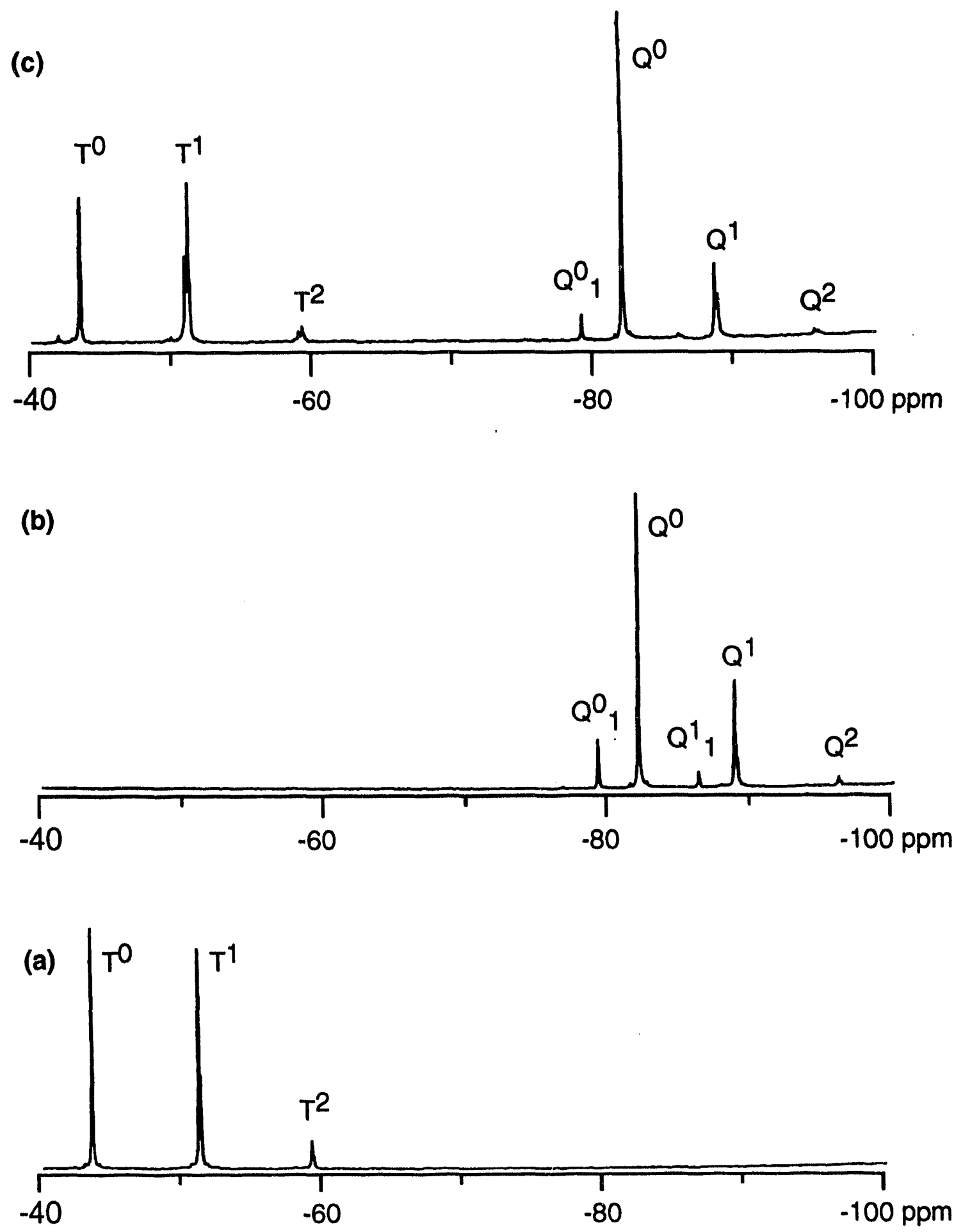

Figure 1. ${ }^{29} \mathrm{Si}$ NMR of (a) MTEOS, (b) TEOS, and (c) the hybrid 50 MTEOS : 50 TEOS sol-gel systems. 
formed by self-condensation of pure monomers. Figs $2(\mathrm{c})$ and (d) show the $\mathrm{T}^{1}$ and $\mathrm{Q}^{1}$ regions of the spectrum of the hybrid sol-gel. In addition to the resonances of self-condensed species, there are several resonances which correspond to cross-condensed species. These assignments were made in a similar fashion to those above and are also listed in Table 1.

Table I. ${ }^{29} \mathrm{Si}$ Peak assignments for the system MTEOS- TEOS sol-gel system.

\begin{tabular}{|c|c|c|}
\hline observed silicon (underlined) & Abbr. & $\begin{array}{c}\text { Chem. shift } \\
\text { (ppm) }\end{array}$ \\
\hline \multicolumn{3}{|l|}{ MTEOS Species } \\
\hline $\mathrm{CH}_{3} \mathrm{Si}\left(\mathrm{OC}_{2} \mathrm{H}_{5}\right)_{3}$ & $\mathrm{~T}^{0}$ & -44.37 \\
\hline $\mathrm{CH}_{3} \mathrm{Si}\left(\mathrm{OC}_{2} \mathrm{H}_{5}\right)_{2}-\mathrm{O}-\mathrm{Si}\left(\mathrm{OC}_{2} \mathrm{H}_{5}\right)_{2}\left(\mathrm{CH}_{3}\right)$ & & -51.04 \\
\hline $\mathrm{CH}_{3} \mathrm{Si}\left(\mathrm{OC}_{2} \mathrm{H}_{5}\right)_{2}-\mathrm{O}-\mathrm{Si}\left(\mathrm{OC}_{2} \mathrm{H}_{5}\right)\left(\mathrm{CH}_{3}\right)(\mathrm{O}-)$ & $\mathrm{T}^{1}$ & -51.16 \\
\hline \multicolumn{3}{|l|}{ TEOS Species } \\
\hline $\mathrm{Si}\left(\mathrm{OC}_{2} \mathrm{H}_{5}\right) 4$ & $Q^{0}$ & -82.00 \\
\hline $\mathrm{Si}\left(\mathrm{OC}_{2} \mathrm{H}_{5}\right)_{3}-\mathrm{O}-\mathrm{Si}\left(\mathrm{OC}_{2} \mathrm{H}_{5}\right)_{3}$ & $\underline{Q}^{1-} Q^{1}$ & -88.85 \\
\hline $\mathrm{Si}\left(\mathrm{OC}_{2} \mathrm{H}_{5}\right)_{3}-\mathrm{O}-\mathrm{Si}\left(\mathrm{OC}_{2} \mathrm{H}_{5}\right)_{2}(\mathrm{O}-)$ & $\underline{Q}^{1}-Q^{2}$ & -89.02 \\
\hline \multicolumn{3}{|l|}{ Hybrid Species } \\
\hline $\mathrm{CH}_{3} \mathrm{Si}\left(\mathrm{OC}_{2} \mathrm{H}_{5}\right)_{2}-\mathrm{O}-\mathrm{Si}\left(\mathrm{OC}_{2} \mathrm{H}_{5}\right)_{3}$ & $\mathrm{~T}^{1}-\mathrm{Q}^{1}$ & -50.79 \\
\hline $\mathrm{CH}_{3} \mathrm{Si}\left(\mathrm{OC}_{2} \mathrm{H}_{5}\right)_{2}-\mathrm{O}-\mathrm{Si}\left(\mathrm{OC}_{2} \mathrm{H}_{5}\right)_{2}(\mathrm{O}-)$ & $\mathrm{T}^{1}-\mathrm{Q}^{2}$ & -50.90 \\
\hline $\mathrm{Si}\left(\mathrm{OC}_{2} \mathrm{H}_{5}\right)_{3}-\mathrm{O}-\mathrm{Si}\left(\mathrm{OC}_{2} \mathrm{H}_{5}\right)_{2}\left(\mathrm{CH}_{3}\right)$ & $Q^{1-T^{1}}$ & -88.61 \\
\hline$\underline{\mathrm{Si}}\left(\mathrm{OC}_{2} \mathrm{H}_{5}\right)_{3}-\mathrm{O}-\mathrm{Si}\left(\mathrm{OC}_{2} \mathrm{H}_{5}\right)(\mathrm{O}-)\left(\mathrm{CH}_{3}\right)$ & $\underline{Q}^{1}-T^{2}$ & -88.73 \\
\hline
\end{tabular}

The relative rates of self- versus cross-condensation are reflected in the distribution of TT, TQ and QQ bonds. To simplify the analysis, we only considered dimeric species for this water limited system. The experimental ratio of $\mathrm{T}^{1} \mathrm{~T}^{1}: \mathrm{T}^{1} \mathrm{Q}^{1}: \mathrm{Q}^{1} \mathrm{Q}^{1}$ species is $0.45: 0.45: 0.10$. To predict the distribution of species we first calculated the relative number of $T$ and $Q$ silicons which participated in the formation of dimeric species. We assume that these silicons existed as hydrolyzed species during the initial stages of the reaction and that the condensation reaction is second order in their concentration. The ratio of products is fixed when either all of the hydrolyzed $T$ or all of the hydrolyzed $Q$ species have been consumed, since at that time, crosscondensation products can no longer be formed. Earlier we found that the MTEOS silicons reacted much faster than the TEOS silicons, thus, the two condensation reaction rates which determine the final product distribution are the self-condensation rate of MTEOS and the crosscondensation rate of MTEOS/TEOS. If these two condensation rates are assumed to be equal, then the predicted ratio of species is $0.46: 0.44: 0.10$. In each case, the total number of dimers is normalized to 1.0. Within experimental error, the predicted ratio of condensed species is equal to the experimental ratio of condensed species. Thus, within the limits of our measurements, the cross-condensation rate of MTEOS/TEOS is equal to the self-condensation rate of MTEOS. 
(c)

\section{T-Region}

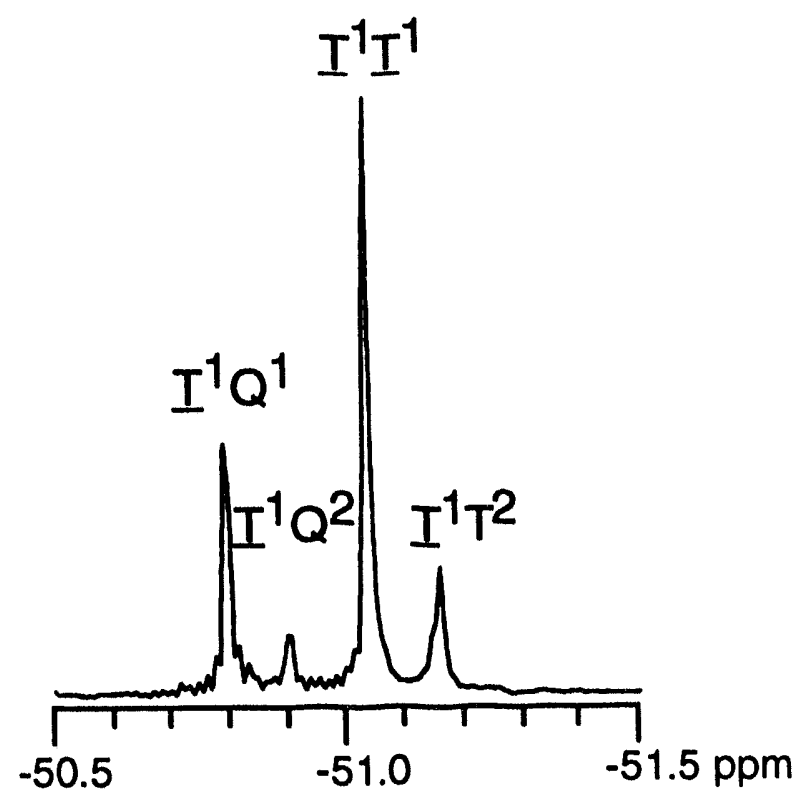

(a)

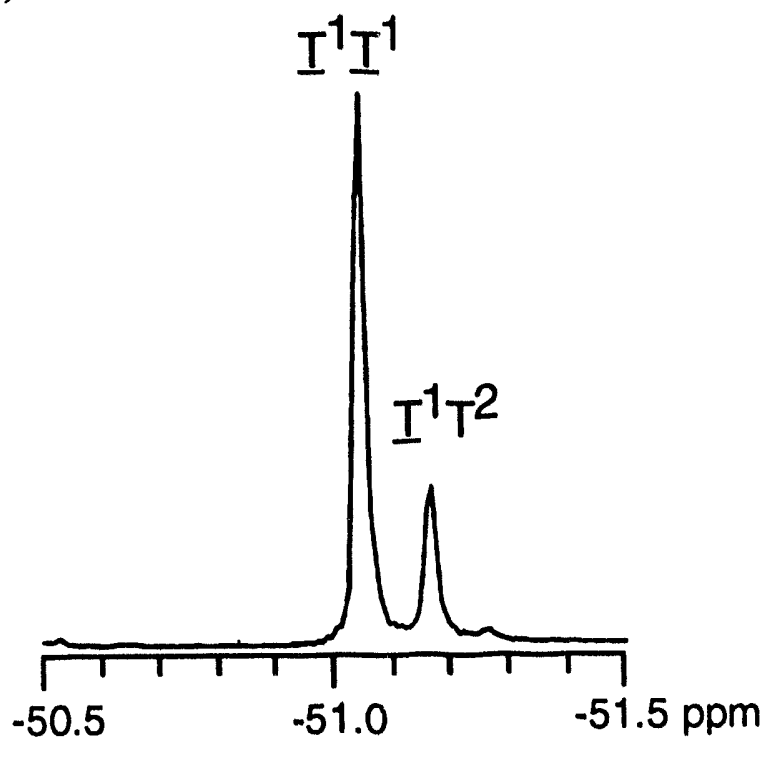

(d)

\section{Q-Region}

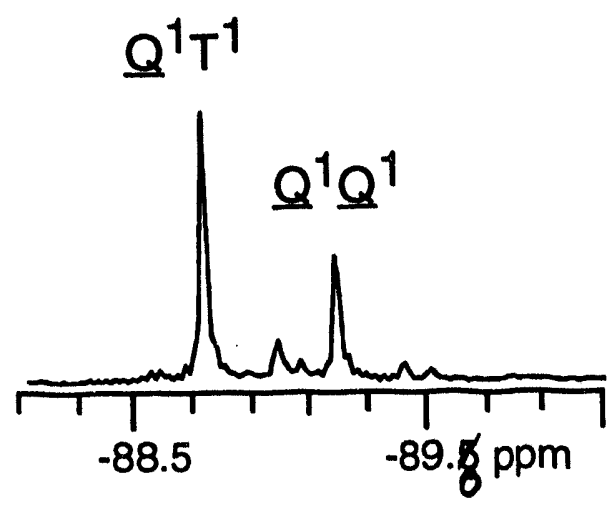

(b)

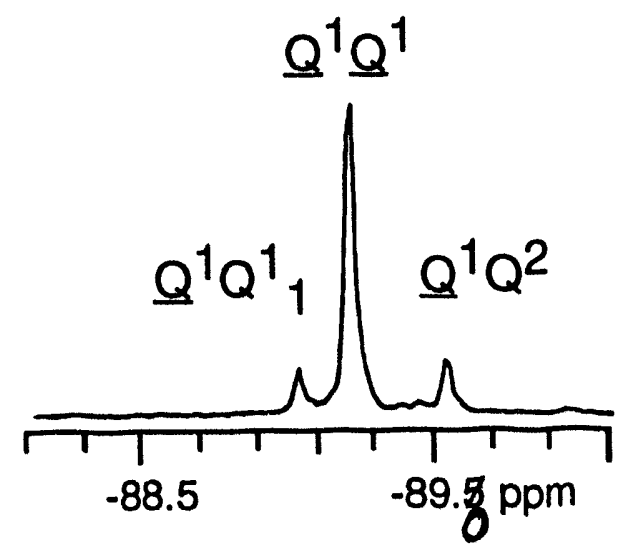

Figure 2. The ${ }^{29} \mathrm{Si}$ NMR spectra of (a) the $\mathrm{T}^{1}$ region of pure MTEOS, (b) the $\mathrm{Q}^{1}$ region of pure TEOS, (c) the $\mathrm{T}^{1}$ region of 50 MTEOS : 50 TEOS and (d) the $\mathrm{Q}^{1}$ region of the 50 MTEOS : 50 TEOS sol gel systems. 


\section{CONCLUSION}

We have measured the atomic level mixing in the hybrid organic-inorganic MTEOSTEOS sol-gel system by means of high resolution ${ }^{29} \mathrm{Si}$ NMR. A simple one dimensional NMR spectrum is capable of distinguishing between self-. and cross-condensation reaction products in the organically modified silica precursor. In addition, the experiment provides information on the relative hydrolysis and condensation reaction rates. We believe that this approach can be used to characterize the local structure of similar highly homogenous multicomponent materials prepared by the sol-gel technique.

\section{REFERENCES}

1. C.J. Brinker and G.W. Scherer, Sol-gel Science: The Physics and Chemistry of Sol-gel Proocessing (Academic Press, San Diego, 1990).

2. Better Ceramics Through Chemistry V edited by M.J. Hampden-Smith, W.G. Klemperer and C.J. Brinker (Mater. Res. Soc. Proc. Pittsburgh, PA, 1992) and references contained therein.

3. R.A. Assink and B.D. Kay, Annu. Rev. Mater. Sci. 21, 491 (1991). D.H. Dcughty, R.A. Assink and B.D. Kay, in Silicon-Based Polymer Science: A Comprehensive Resource Advances in Chemistry Series, edited by J.M. Zeigler, F.W.G. Fearon, (Am. Chem. Soc.,Washington, DC, 1990).

4. C.A. Fyfe, Y. Zhang and P. Aroca, J. Am. Chem. Soc. 114, 3252 (1992),

5. G. Engelhardt and D. Michel, High Resolution Solid State NMR of Silicates and Zeolites (Wiley Publishers, New York, 1987)

6. C.A. Fyfe, Solid State NMR for Chemists (C.F.C. Press, Guelph, Ontario, 1983).

7. R.A. Assink and B.D. Kay, in Better Ceramics Through Chemistry IV, edited by B.J. J. Zelinski, C.J. Brinker, D.E. Clark and D.R. Ulrich (Mater. Res. Soc. Proc. 180, Pittsburgh, PA, 1990) p.21. 
11
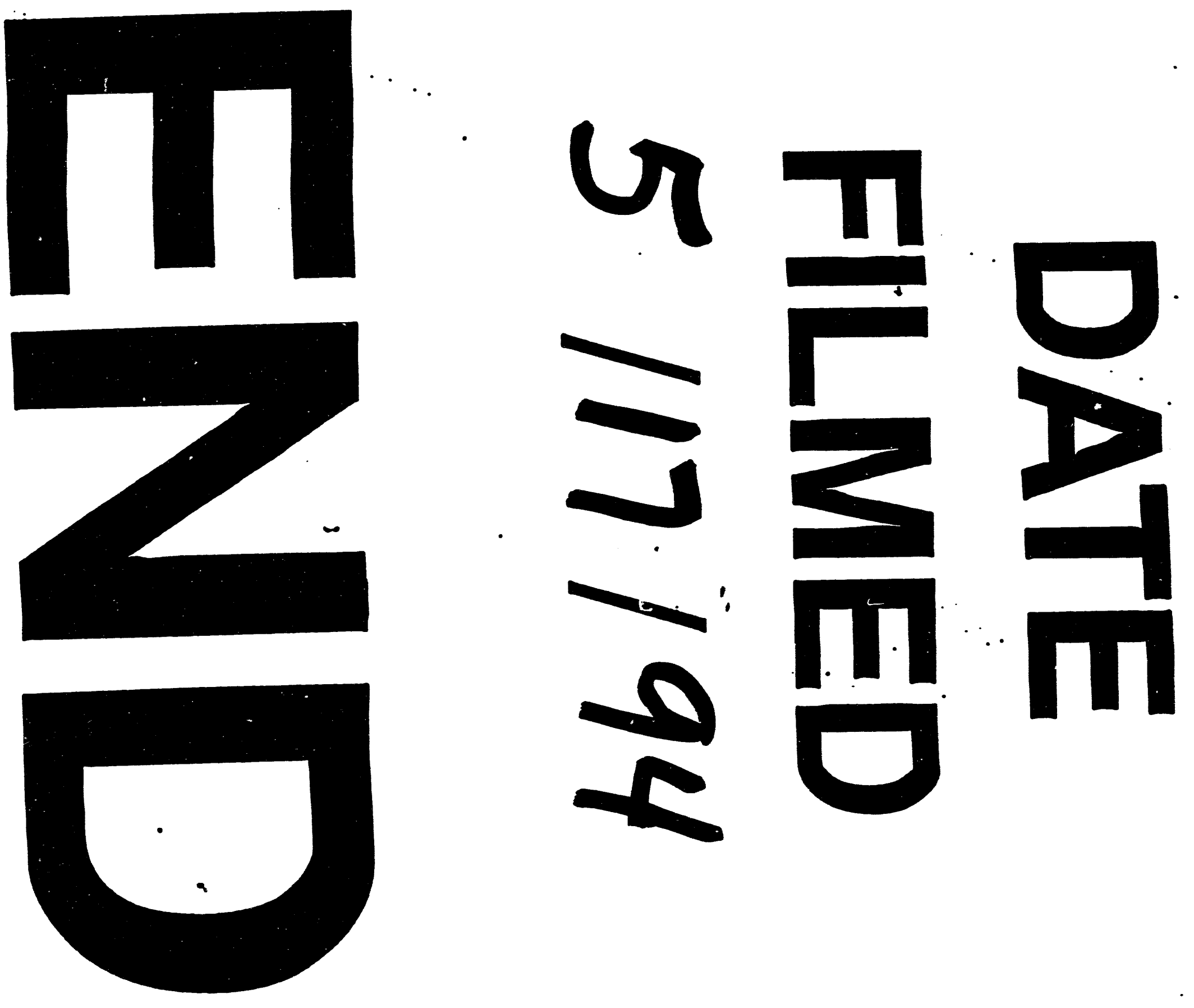


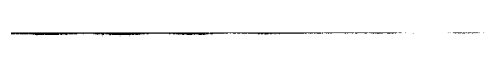

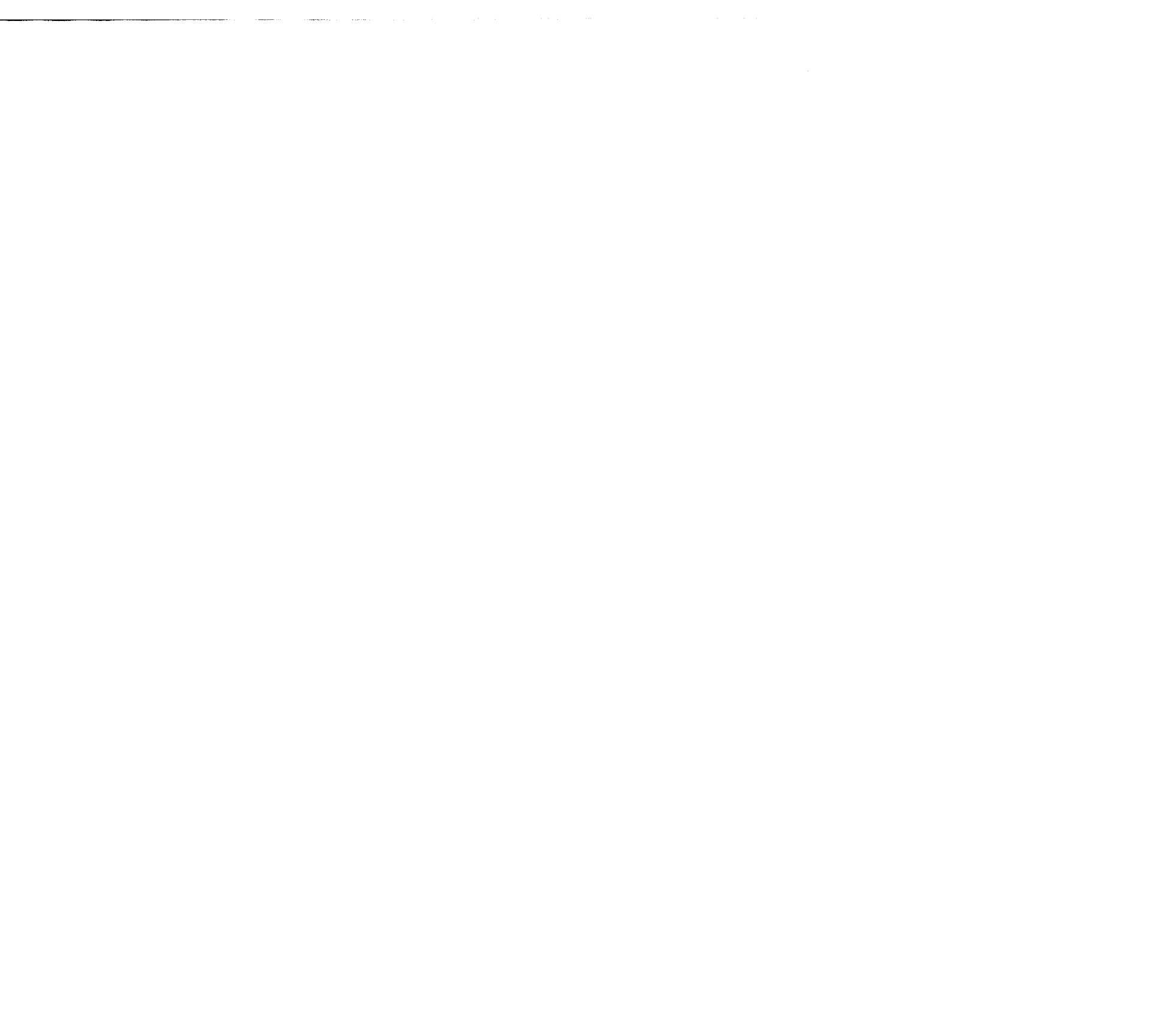

